\title{
ERRATA IN GAUSS'S “TAFEL DER ANZAHL DER CLASSEN BINÄRER QUADRATISCHER FORMEN."
}

BY THE LATE PROFESSOR A. M. NASH.

(Communicated by Professor E. B. ElliotT.)

ON page 141 of the present volume 9 of the Bulletin Professor Hewes has exhibited the details, on Cayley's plan, of the classes of properly primitive reduced forms with the two negative determinants - 468 and -931 , which Perott has shown must be added to those given as irregular by Gauss. There is at present in my charge a mass of calculation and tabulation prepared by the late Professor A. M. Nash, of the Indian Educational Department, who died in 1895 while still engaged on the work. He seems to have possessed methods by which he could tabulate irregular determinants with few if any probable omissions. Unfortunately however his numerical work is accompanied by but little explanation of the methods and their justification. The determinants which he has tabulated as irregular cover a range up to about - 20,000, even indices, indices 3 and 9 , and index 5 being separately dealt with. For about half of them the details of classes are worked out on Cayley's plan, and the composition of the principal genus given. He has also worked out in detail the classes of binary quadratic forms with all negative determinants, both regular and irregular, up to $-2,600$, the results in this section of his research being marked nearly to the end "checked Gauss."

To print the whole is not feasible. The quantity alone would be prohibitive even had the principles and conclusions been left in form for publication. It is hoped however that the manuscript may be placed in some library to which mathematicians who may be desirous in the future of testing and extending the tables, or may be engaged in research on the subject, can have access. What Professor Hewes's note now suggests to me is the desirability of printing the following transcript of a list which is headed by Professor Nash "Errata in Table of Negative Determinants, Gauss, Vol. II." The list 
includes many corrections not given by Schering in his appendix to Gauss's volume, or by Perott.

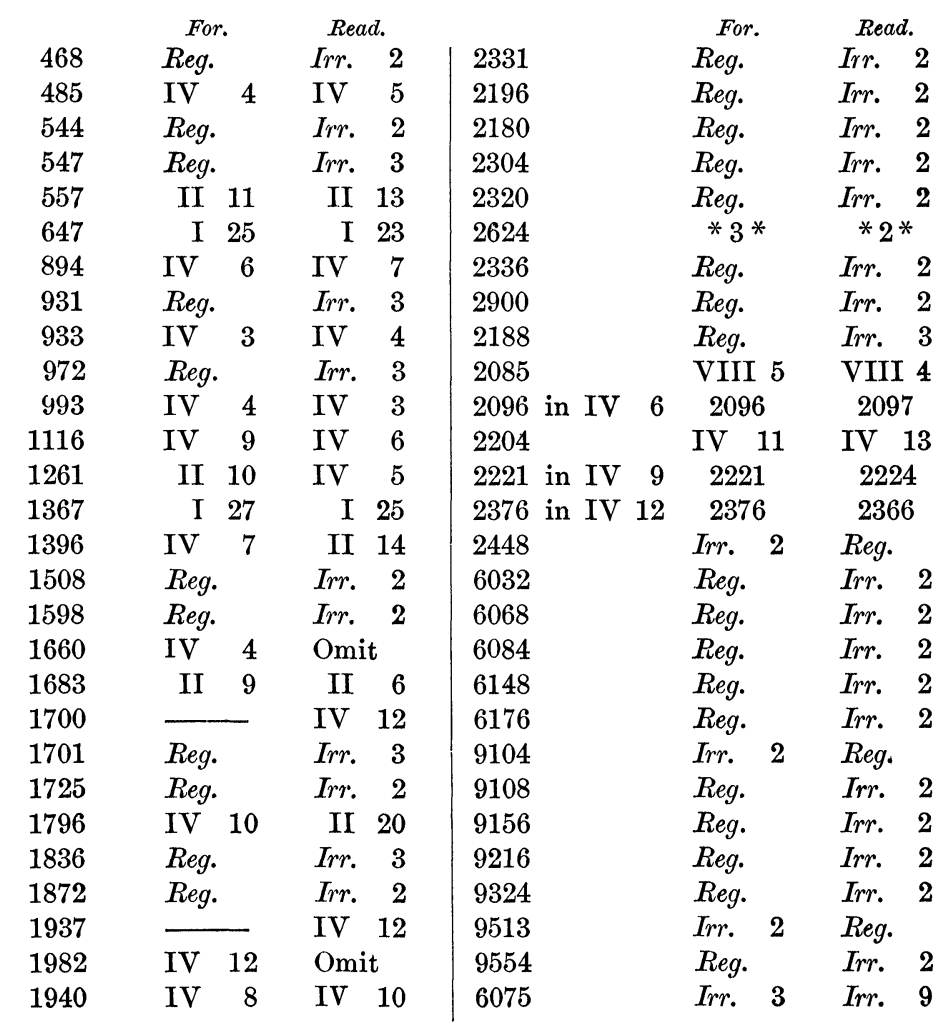

\section{THE LOGARITHM AS A DIRECT FUNCTION.}

BY DR. EMORY MCCLINTOCK.

(Read before the American Mathematical Society, February 28, 1903.)

IN a paper of the same title published in the Annals of Mathematics for January, 1903, Mr. J. W. Bradshaw defines $\log x$ as a direct function of $x$, namely,

$$
\log x=\int_{1}^{x} x^{-1} d x
$$

